\title{
Revista Agrarian \\ ISSN: 1984-2538 \\ Compactação sobre o sulco de plantio e tratamento de sementes na produtividade do arroz de terras altas
}

\section{Compaction on sowing furrow and seed treatment in the upland rice grain yield}

\author{
Veneraldo Pinheiro, Adriano Stephan Nascente, Luis Fernando Stone \\ Embrapa arroz e feijão, Parque Estação Biológica - PqEB s/nº. Brasília, DF - Brasil - CEP 70770-901 \\ Recebido em: 03/06/2016 \\ Aceito em:02/05/2017
}

\begin{abstract}
Resumo: Este trabalho objetivou determinar o efeito da compactação sobre o sulco de plantio e do tratamento de sementes na produtividade do arroz de terras altas cultivado sob sistema plantio direto (SPD). Foram conduzidos quatro experimentos, o primeiro e o terceiro em área de pastagem de Urochloa brizantha, o segundo em área de soja e o quarto em área de pastagem de Urochloa decumbens. No primeiro e no segundo foram comparadas três pressões de compactação sobre o sulco de plantio, no delineamento de blocos ao acaso, com seis repetições. No terceiro e no quarto foram comparados três pressões de compactação sobre o sulco de plantio e dois tratamentos de sementes, em blocos ao acaso, esquema fatorial $(3 \times 2)$, com seis repetições no terceiro e 12 no quarto experimento. No primeiro experimento, as pressões de compactação foram $25 \mathrm{kPa}, 42 \mathrm{kPa}$ e $228 \mathrm{kPa}$ e, nos outros três, a pressão de $228 \mathrm{kPa}$ foi substituída pela de $340 \mathrm{kPa}$. Os tratamentos de sementes foram: T0 - sem tratamento e T1 - fipronil + piraclostrobina + tiofanato metílico. A compactação sobre o sulco de plantio até 340 $\mathrm{kPa}$ aumentou de forma linear a produtividade do arroz. O tratamento de sementes proporcionou maiores produtividades do arroz cultivado no SPD sobre palhada de braquiária. Com base nos resultados, conclui-se que a compactação sobre o sulco de plantio até $340 \mathrm{kPa}$ e o tratamento de sementes foram importantes práticas para proporcionar incrementos significativos na produtividade de grãos do arroz de terras altas.
\end{abstract}

Palavras-chave: Oryza sativa, plantio direto, palhada de braquiária

Abstract: This study aimed to determine the effect of compaction on sowing furrow and seed treatment on grain yield of upland rice cultivated under no-tillage system (NTS). Four experiments were carried out; the first and the third one in Urochloa brizantha pasture area, the second one in soybean area and the fourth one in Urochloa decumbens pasture area. In the first and second experiments, three compaction pressures on the sowing furrow, in the design of randomized blocks with six replications, were compared. In the third and fourth experiments, three compaction pressures on the sowing furrow and two seed treatments, in a randomized block factorial $(3 \times 2)$ with six repetitions in the third one and 12 in the fourth one, were compared. In the first experiment, the compaction pressures were $25 \mathrm{kPa}, 42 \mathrm{kPa}$, and $228 \mathrm{kPa}$ and, in the three others, the pressure of $228 \mathrm{kPa}$ was replaced by $340 \mathrm{kPa}$. The seed treatments were: $\mathrm{T} 0$ - without treatment and $\mathrm{T} 1$ - fipronil + pyraclostrobin + thiophanate methyl. The compaction on the sowing furrow up to $340 \mathrm{kPa}$ linearly increased rice grain yield. Seed treatment resulted in higher yields of rice grown in the NTS on Urochloa straw. Based on the results, it was concluded that soil compaction on the sowing furrow up to $340 \mathrm{kPa}$ and seed treatment were important practices to provide significant increases in grain yield of upland rice.

Keywords: no-tillage, Oryza sativa, Urochloa straw

\section{Introdução}

O sistema plantio direto (SPD), devido aos benefícios ao ambiente, tais como maior conservação de água, aumento da fertilidade do solo, do teor de matéria orgânica e da proteção do solo contra erosão, tem tido significativo crescimento em nível mundial. Os cinco países com maior área sob esse sistema são Estados Unidos, Brasil, Argentina, Canadá e Austrália, com 35,6; 31,$8 ; 29,2 ; 18,3$ e 17,7 milhões de hectares, respectivamente (FAO, 2015).

Pinheiro et al., v.11, n.39, p. 6-13, Dourados, 2018 


\section{(1) \\ Revista Agrarian \\ ISSN: 1984-2538}

Embora parte significativa da área de cerca de 50 milhões de hectares ocupada pela agricultura brasileira esteja sob SPD (Nascente \& Crusciol, 2012), o arroz de terras altas, produzido somente com águas da chuva, sem irrigação, não tem tido desenvolvimento adequado sob esse sistema (Crusciol et al., 2010; Nascente et al., 2011; Nascente et al., 2013). Assim, é importante desenvolver tecnologias para atingir altas produtividades de arroz no SPD, visando a sustentabilidade da agricultura, aumentando a produção de alimentos e economizando mais água (Farooq et al., 2009).

No SPD, a camada de 0-0,05 $\mathrm{m}$ do solo geralmente apresenta elevada porosidade total graças à ação dos discos da semeadora-adubadora, maior concentração de raízes e de matéria orgânica, maior atividade biológica e mais ciclos de umedecimento e secagem (Collares et al., 2006; Reichert et al., 2009), o que pode dificultar o contato das sementes de arroz com o solo. Neste contexto, a compactação sobre o sulco de plantio feita pela roda compactadora da semeadoraadubadora melhora o contato do solo com as sementes, permitindo que elas absorvam água mais cedo e germinem mais rapidamente (Modolo et al., 2007). O uso dessa prática proporcionou aumentos de $40 \%$ no estande de plantas e de $15 \%$ na produtividade do arroz cultivado em várzea (Soares \& Carrão, 1993). Portugal et al. (2013), ao compactarem o solo sobre o sulco de plantio pela passagem de um trator com massa de $1.600 \mathrm{~kg}$, constataram acréscimo de $17 \%$ na produtividade do arroz de terras altas conduzido em SPD, em relação à não-compactação.

Outro problema que pode causar decréscimo na produtividade do arroz sob SPD é o dano por cupins (Procornitermes araujoi, Procornitermes triacifer e Syntermes molestus). Esses insetos ocorrem na maior parte das lavouras de arroz de terras altas estabelecidas em solos de Cerrado, sendo uma das principais causas do uso de inseticidas em tratamento de sementes (Ferreira et al., 2007). No
SPD o problema é agravado, pois ele propicia acúmulo de palhada na superfície do solo, aumentando a disponibilidade de alimento para os cupins, podendo ocasionar perda total da produção (Barbosa et al., 2009). Ademais, nesse sistema não há diminuição da população desses insetos pela exposição, esmagamento e destruição de galerias, como acontece no preparo convencional. Uma das alternativas para minimizar o seu dano é compactar o solo sobre o sulco de plantio. Barrigossi et al. (2011) observaram que o ataque de cupins no arroz de terras altas cultivado em plantio direto foi menor nos tratamentos com compactação (1,9 e 5,5 kgf cm ${ }^{2}$ ) sobre o sulco do que no sem compactação e que o benefício dessa prática é reforçado quando associado ao tratamento de sementes com inseticidas.

O objetivo deste trabalho foi determinar o efeito da compactação sobre o sulco de plantio e do tratamento de sementes na produtividade do arroz de terras altas cultivado no sistema plantio direto.

\section{Material e Métodos}

O trabalho foi conduzido na Fazenda Capivara, da Embrapa Arroz e Feijão, situada no município de Santo Antônio de Goiás, GO, cujas coordenadas geográficas são: latitude $16^{\circ} 28^{\prime} 00^{\prime \prime} \mathrm{S}$, longitude $49^{\circ} 17^{\prime} 00^{\prime}$ 'W e altitude de $823 \mathrm{~m}$. O clima, conforme classificação de Köppen, é Aw, tropical de savana, megatérmico. O regime pluvial é bem definido, com período chuvoso de outubro a abril e seco de maio a setembro, com precipitação média anual de $1485 \mathrm{~mm}$. O solo é um Latossolo Vermelho ácrico típico (Santos et al., 2013), de textura argilosa, com teores médios de $530 \mathrm{~g} \mathrm{~kg}^{-1} \mathrm{de}$ areia, $40 \mathrm{~g} \mathrm{~kg}^{-1}$ de silte e $430 \mathrm{~g} \mathrm{~kg}^{-1}$ de argila, na camada de 0-0,20 m.

Foram instalados quatro experimentos com a cultura do arroz de terras altas, em sistema plantio direto, cujos resultados da análise química inicial da camada de 0-0,20 m são apresentados na Tabela 1. 


\section{(0) \\ Revista Agrarian \\ ISSN: 1984-2538}

Tabela 1. Resultado da análise química inicial da camada de 0-0,20 m do solo das áreas onde foram conduzidos os experimentos com arroz de terras altas. $1^{\circ}$ experimento sobre palhada de Urochloa brizantha e $2^{\circ}$ experimento sobre palhada de soja, conduzidos em $2010,3^{\circ}$ experimento sobre palhada de Urochloa brizantha e $4^{\circ}$ experimento sobre palhada de Urochloa decumbens, conduzidos em 2011.

\begin{tabular}{|c|c|c|c|c|c|c|c|c|c|c|c|}
\hline pH $\left(\mathrm{H}_{2} \mathrm{O}\right)$ & $\mathrm{Ca}^{2+}$ & $\mathbf{M g}^{2+}$ & $\begin{array}{l}\mathbf{A l}^{3+} \\
\mathbf{l}_{\mathrm{c}} \mathrm{dm}^{-}\end{array}$ & $\mathbf{H}^{+}+\mathbf{A l}^{+}$ & $\mathbf{P}$ & $\mathbf{K}^{+}$ & $\begin{array}{l}\mathrm{Cu}^{2+} \\
--\mathrm{mg}\end{array}$ & $\begin{array}{l}\mathbf{Z n}^{2+} \\
\mathrm{lm}^{-3}--\end{array}$ & $\mathrm{Fe}^{3+}$ & $\mathrm{Mn}^{2+}$ & $\begin{array}{l}\text { M.O. } \\
\text { g kg }^{-1}\end{array}$ \\
\hline \multicolumn{12}{|c|}{$1^{\circ}$ Experimento } \\
\hline 5,7 & 14,0 & 7,0 & 1,0 & 50,0 & 3,0 & 90,0 & 2,5 & 2,2 & 32,0 & 25,0 & 24,0 \\
\hline 6,0 & 18,9 & 8,7 & 0,3 & 32,2 & $\begin{array}{l}2,7 \\
\text { eerin }\end{array}$ & $\begin{array}{l}73,0 \\
\text { to }\end{array}$ & 2,4 & 2,3 & 34,0 & 29,0 & 20,0 \\
\hline \multicolumn{12}{|c|}{$4^{\circ} \mathrm{E}$} \\
\hline 6,2 & 16,5 & 8,0 & 0,0 & 16,0 & 2,5 & 82,0 & 2,4 & 3,1 & 34,5 & 30,0 & 23,0 \\
\hline
\end{tabular}

Nos dois primeiros foram comparadas três pressões de compactação sobre o sulco de plantio, no delineamento de blocos ao acaso, com seis repetições. As pressões de compactação aplicadas no primeiro experimento foram: $25 \mathrm{kPa}$, proporcionada pelo compactador original da roda "V" da semeadora-adubadora; $42 \mathrm{kPa}$, proporcionada por uma roda com pneu de massa de 96,6 kg colocada atrás de cada linha da semeadoraadubadora e $228 \mathrm{kPa}$, proporcionada pela passada da roda do trator em cada linha, logo após a semeadura. O trator utilizado foi o MF $265 \mathrm{com}$ pneu direcional 7.50-16 TD 92 com três "treads", sem lastro adicional, com massa de $520 \mathrm{~kg}$ no eixo dianteiro. Após a condução do $1^{\circ}$ experimento, percebeu-se que a pressão aplicada na linha de semeadura ainda poderia ser aumentada sem compactar o solo em demasia, o que possivelmente aumentaria o seu efeito no controle de insetospragas e na produtividade do arroz. Dessa forma, no segundo experimento, a pressão de $228 \mathrm{kPa}$ foi substituída pela de $340 \mathrm{kPa}$, proporcionada pela passagem da roda do mesmo trator na linha de semeadura, mas aumentando a massa no eixo dianteiro para $800 \mathrm{~kg}$, pelo uso de lastro adicional. Nos dois últimos foram comparados três pressões de compactação sobre o sulco de plantio e dois tratamentos de sementes, no delineamento de blocos ao acaso, esquema fatorial, com seis repetições no terceiro experimento e 12 no quarto. As pressões de compactação aplicadas nesses experimentos foram iguais às aplicadas no segundo experimento. Os tratamentos de sementes foram: T0 - sem tratamento e T1 - fipronil + piraclostrobina + tiofanato metílico

$(156+1,56+126,6 \mathrm{~mL}$ i.a./100 kg sementes). Esse produto é uma mistura pronta de um inseticida e dois fungicidas, agindo nos insetos-pragas que atacam a cultura na sua fase inicial e no controle de fungos transmitidos via semente, sendo amplamente usado na cultura do arroz (Santos et al., 2006).

$\mathrm{O}$ primeiro experimento foi instalado em 21/01/2010, sobre palhada dessecada de Urochloa brizantha implantada em novembro de 2002, em parcelas de 73,0 x 1,6 m, com a cultivar de arroz de terras alta Sertaneja, no espaçamento de $0,40 \mathrm{~m}, 75$ sementes por metro, tratadas com fipronil + piraclostrobina + tiofanato metílico $(156+1,56+$ $126,6 \mathrm{~mL}$ i.a. $/ 100 \mathrm{~kg}$ sementes). Antes da semeadura, em 04/01/2010, foram aplicados $59 \mathrm{~kg}$ $\mathrm{ha}^{-1}$ de ureia e, em 18/01/2010, foram aplicados os herbicidas paraquat ( $300 \mathrm{~g}$ i.a. ha $\left.{ }^{-1}\right)$ e pendimetalina $\left(1.500\right.$ g i.a. ha $\left.^{-1}\right)$. Em 30/01/2010, foi aplicado o herbicida metsulfurom metílico $\left(2,4 \mathrm{~g}\right.$ i.a. $\left.\mathrm{ha}^{-1}\right)$. A semeadura foi feita com semeadora-adubadora, com sistema de facão com guilhotina. A adubação de base foi feita com $292 \mathrm{~kg} \mathrm{ha}^{-1}$ da fórmula comercial 5-30-15. Foram realizadas duas adubações de cobertura com $88 \mathrm{~kg} \mathrm{ha}^{-1}$ de ureia, em 22/01 e $12 / 02 / 2010$. Foram feitas quatro irrigações de 22 $\mathrm{mm}$ cada, no final do ciclo da cultura, com carretel enrolador. A colheita foi realizada em 20/05/2010.

$\mathrm{O}$ segundo experimento foi instalado em 28/01/2010, sobre palhada de soja implantada após três anos de pastagem de $U$. brizantha, em parcelas

Pinheiro et al., v.11, n.39, p. 6-13 , Dourados, 2018 


\section{(0) \\ Revista Agrarian \\ ISSN: 1984-2538}

de 142,0 x 1,6 m, com a cultivar Pepita. O inseticida tiametoxam ( $150 \mathrm{~g}$ i.a. ha $\left.^{-1}\right)$ foi misturado ao adubo. A mistura do inseticida granulado com o adubo substitui a prática de tratar as sementes no controle dos insetos-pragas que atacam a cultura na sua fase inicial. Em 25/01/2010 foram aplicados os herbicidas paraquat ( $300 \mathrm{~g}$ i.a. $\left.\mathrm{ha}^{-1}\right)$ e pendimetalina $\left(800\right.$ g i.a. ha $\left.^{-1}\right)+$ espalhante adesivo Assist (óleo mineral) (378 g i.a. ha ${ }^{-1}$ ) e, em 06/02/2010, o herbicida oxadiazona $\left(1000 \mathrm{~g}\right.$ i.a. ha $\left.{ }^{-1}\right)$. A semeadura foi feita com a mesma semeadoraadubadora usada no primeiro experimento. A adubação de base foi feita com $350 \mathrm{~kg} \mathrm{ha}^{-1} \mathrm{da}$ fórmula comercial 5-30-15. Foi realizada uma adubação de cobertura com $60 \mathrm{~kg} \mathrm{ha}^{-1}$ de ureia, em $12 / 02 / 2010$. Foram feitas quatro irrigações de 22 $\mathrm{mm}$ cada, no final do ciclo da cultura, com carretel enrolador. A colheita foi realizada em 10/06/2010, sendo no $1^{\circ}$ experimento feita em $116,8 \mathrm{~m}^{2}$ (quatro linhas de $73 \mathrm{~m}$ ) e no $2^{\circ}$ em $227,2 \mathrm{~m}^{2}$ (quatro linhas de $142 \mathrm{~m}$ ).

$\mathrm{O}$ terceiro experimento foi instalado em $31 / 01 / 2011$ e o quarto em 01/02/2011, os quais foram conduzidos, respectivamente, sobre palhada dessecada de Urochloa brizantha, implantada em novembro de 2002, e de $B$. decumbens, implantada também em novembro de 2002. O terceiro experimento foi instalado em parcelas de $20 \times 2,25$ $\mathrm{m}$ e o quarto em parcelas de $6 \times 2,25 \mathrm{~m}$, ambos com a cultivar de arroz de terras alta Pepita, no espaçamento de $0,45 \mathrm{~m}$, com 90 sementes por metro. Em 03/02/11, nos dois experimentos, foram aplicados os herbicidas paraquat $\left(200 \mathrm{~g}\right.$ i.a. ha $\left.{ }^{-1}\right) \mathrm{e}$ pendimetalina ( $800 \mathrm{~g}$ i.a. ha $\left.^{-1}\right)+$ espalhante adesivo etilenoxi $\left(20\right.$ g i.a. ha $\left.{ }^{-1}\right)$. A semeadura foi feita com semeadora-adubadora, com sistema de facão com guilhotina. A adubação de base foi feita com $341 \mathrm{~kg}$ $\mathrm{ha}^{-1}$ da fórmula comercial 5-30-15. Foram realizadas quatro adubações de cobertura com ureia, em 01/02 $\left(158 \mathrm{~kg} \mathrm{ha}^{-1}\right), 18 / 02\left(83 \mathrm{~kg} \mathrm{ha}^{-1}\right), 15 / 03\left(83 \mathrm{~kg} \mathrm{ha}^{-1}\right)$ e 29/03/2011 (115 kg ha-1). No terceiro experimento foram feitas quatro irrigações de $22 \mathrm{~mm}$ cada, em $17 / 04,21 / 04,25 / 04$ e 29/04/2011, com carretel enrolador. No quarto experimento foram três irrigações, em 19/04, 22/04 e 28/04/2011. A colheita do terceiro experimento foi realizada em 12/05/2011, em $27 \mathrm{~m}^{2}$ (três linhas de $20 \mathrm{~m}$ ) por parcela, e a do quarto experimento em 17/05/2011, em $8,1 \mathrm{~m}^{2}$ (três linhas de $6 \mathrm{~m}$ ) por parcela.

Foi determinada a produtividade de grãos em todos experimentos por meio da colheita dos grãos, pesagem, correção da umidade para $13 \%$, cálculo da produção por área colhida e transformação para $\mathrm{kg}$ $\mathrm{ha}^{-1}$. Os dados foram submetidos à análise de variância, utilizando-se o procedimento GLM do programa estatístico SAS (SAS Institute, 2002). Foi feita também a análise de regressão para determinar o efeito das pressões de compactação na produtividade do arroz.

\section{Resultados e Discussão}

Os tratamentos de pressão de compactação sobre o sulco de plantio afetaram significativamente a produtividade do arroz de terras altas nos quatro experimentos (Tabelas 2 e 3), a qual aumentou linearmente com o incremento da pressão de compactação (Figura 1).

Tabela 2. Resumo da análise de variância para produtividade do arroz nos experimentos conduzidos em 2010 sobre palhada de Urochloa brizantha $\left(1^{\circ}\right.$ experimento) e de soja ( $2^{\circ}$ experimento).

\begin{tabular}{lcccccc}
\multicolumn{1}{c}{ Fonte de variação } & GL & Quadrado médio & & GL & Quadrado médio \\
\cline { 1 - 3 } & & $1^{\circ}$ experimento & & & $2^{\text {o }}$ experimento \\
\hline Bloco & 5 & $593.365^{*}$ & & 5 & $860.762^{*}$ \\
Pressão de compactação & 2 & $1.923 .222^{* *}$ & & 2 & $6.217 .060^{* *}$ \\
Resíduo & 10 & 123.903 & & 10 & 168.487 \\
\hline CV $(\%)$ & & 8,3 & & & 33,0 \\
\hline
\end{tabular}

*,**Significativo a 0,05 e 0,01 pelo teste $\mathrm{F}$, respectivamente

Ademais, constatou-se que não houve interação significativa entre o tratamento de sementes e a pressão de compactação do solo no sulco de plantio, no terceiro e quatro experimentos (Tabela 3 ). 


\section{(0) \\ Revista Agrarian \\ ISSN: 1984-2538}

Isso significa que o tratamento de sementes apresentou o mesmo comportamento em todas as pressões de compactação, com aumento da produtividade na presença do tratamento, e que a pressão de compactação apresentou o mesmo comportamento tanto na presença como na ausência do tratamento de sementes, com aumento da produtividade com o incremento da pressão.

Tabela 3. Resumo da análise de variância para produtividade do arroz nos experimentos conduzidos em 2011 sobre palhada de Urochloa brizantha ( $3^{\circ}$ experimento) e de Urochloa decumbens ( $4^{\circ}$ experimento).

\begin{tabular}{|c|c|c|c|c|}
\hline Fonte de variação & GL & Quadrado médio & GL & Quadrado médio \\
\hline & \multicolumn{2}{|c|}{$3^{\circ}$ experimento } & \multicolumn{2}{|c|}{$4^{\circ}$ experimento } \\
\hline Bloco & 5 & $506.447^{\mathrm{ns}}$ & 11 & $873.196^{\mathrm{ns}}$ \\
\hline Pressão de compactação (P) & 2 & $6.440 .330 * *$ & 2 & $23.820 .374 * *$ \\
\hline Tratamento de sementes (TS) & 1 & $5.011 .628 * *$ & 1 & $7.731 .623 * *$ \\
\hline Interação P x TS & 2 & $175.036^{\mathrm{ns}}$ & 2 & $569.516^{\mathrm{ns}}$ \\
\hline Resíduo & 25 & 373.714 & 55 & 465.866 \\
\hline
\end{tabular}

CV $(\%)$

ns, **Não significativo e significativo a 0,01 pelo teste $\mathrm{F}$, respectivamente

Assim, constata-se que o tratamento de sementes proporcionou incrementos na produtividade de grãos do arroz de 2606 para $3352 \mathrm{~kg} \mathrm{ha}^{-1}$ no terceiro experimento e de 1045 para $1701 \mathrm{~kg} \mathrm{ha}^{-1}$ no quarto experimento (Tabela 4). Da mesma forma, Pinheiro et al. (2016a, 2016b, 2016c e 2016d) mostraram que o tratamento de sementes foi eficaz para proporcionar incrementos na produtividade de grãos de arroz de terras altas. Os autores atribuíram esse resultado à redução dos danos causados ao arroz por insetos do solo. Corroborando essa informação, Barrigossi \& Ferreira (2001) constataram que o tratamento de sementes com inseticidas aumentou a produtividade do arroz de terras altas em relação ao controle sem tratamento em virtude da redução da mortalidade de plantas pelo ataque de cupins e lagarta-elasmo (Elasmopalpus lignosellus), o que também foi verificado por Ferreira et al. (2007) e Pinheiro et al. (2016a). O tratamento de sementes é especialmente importante no SPD, pois, segundo Barbosa et al. (2009), o acúmulo de palhada na superfície do solo nesse sistema aumenta a disponibilidade de alimento para os cupins, podendo ocasionar perda total da produção.

Tabela 4. Efeito do tratamento de sementes e da pressão de compactação do solo no sulco de plantio na produtividade de grãos do arroz de terras altas.

\begin{tabular}{ccccc}
\hline \multirow{2}{*}{ Pressão de compactação $(\mathbf{k P a})$} & \multicolumn{4}{c}{ Tratamento de sementes } \\
\cline { 2 - 5 } & \multicolumn{2}{c}{ Sem } & Com & \multicolumn{2}{c}{ Sem } & Com \\
\cline { 2 - 5 } & \multicolumn{2}{c}{$3^{\text {o }}$ experimento } & 470 & 784 \\
\hline 25 & 1931 & 2909 & 532 & 1444 \\
42 & 2325 & 3090 & 2134 & 2875 \\
340 & 3560 & 4056 & $1045 \mathrm{~b}$ & $1701 \mathrm{a}$ \\
\hline Média & $2606 \mathrm{~b}$ & $3352 \mathrm{a}$ & & \\
\hline
\end{tabular}


Revista Agrarian

ISSN: 1984-2538

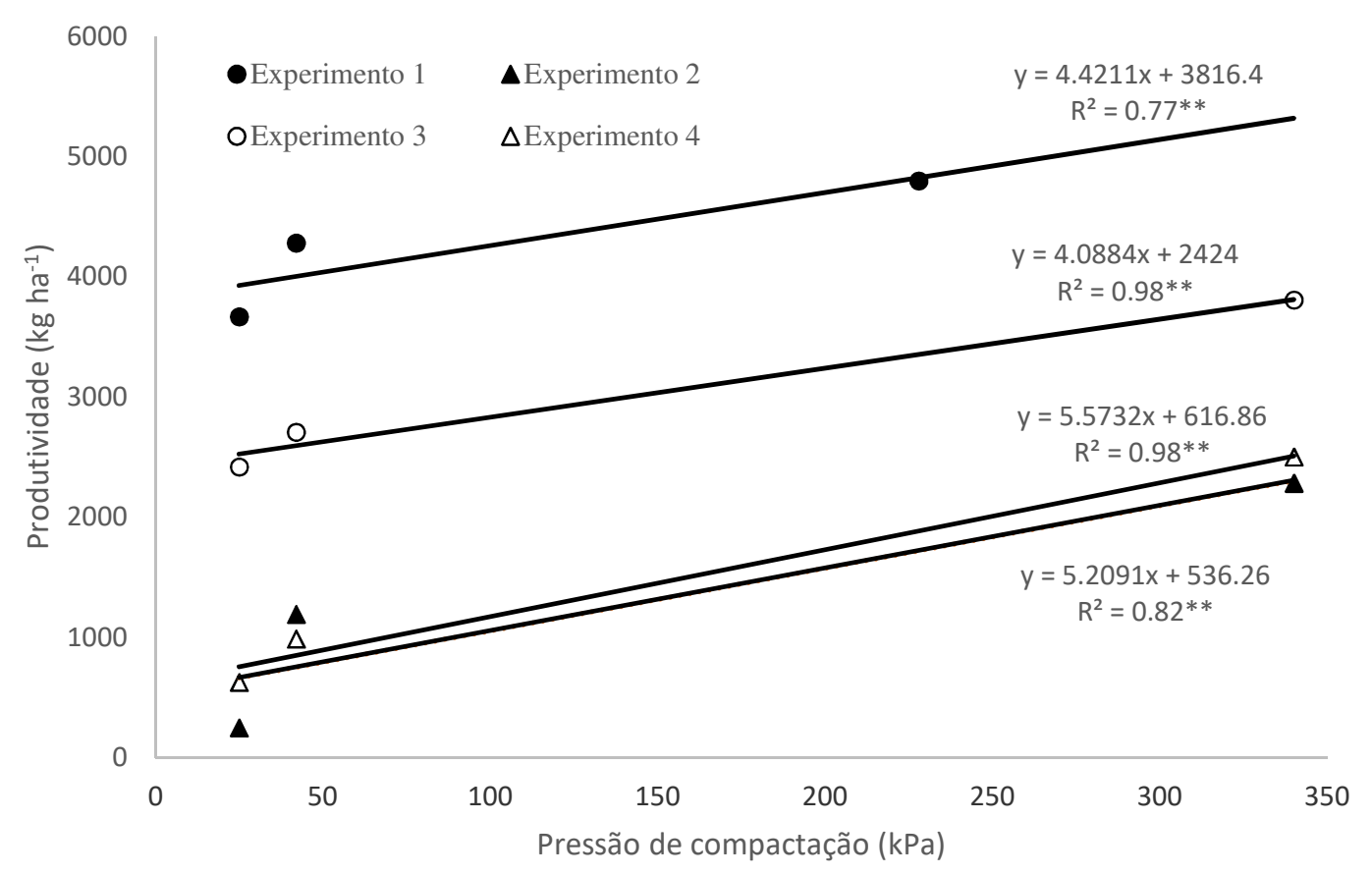

Figura 1. Produtividade do arroz de terras altas em função da pressão de compactação sobre o sulco de plantio nos experimentos conduzidos em 2010 sobre palhada de Urochloa brizantha $\left(1^{\circ}\right.$ experimento) e de soja ( $2^{\circ}$ experimento) e em 2011 sobre palhada de Urochloa brizantha ( $3^{\circ}$ experimento) e de Urochloa decumbens ( $4^{\circ}$ experimento).

De acordo com as equações de regressão, a maior pressão de compactação proporcionou aumentos de $23 \%$ e $51 \%$ na produtividade de grãos do arroz cultivado em SPD sobre palhada de $U$. brizantha, em relação ao uso da roda "V" da semeadora-adubadora. Sobre palhadas de soja e de $U$. decumbens $\mathrm{o}$ aumento foi ainda mais significativo, $162 \%$ e $232 \%$. Nesses dois experimentos, o ataque de cupins foi mais intenso. Pinheiro et al. (2016d), em arroz cultivado em SPD sobre palhada de $U$. brizantha, também observaram aumento na produtividade de grãos, sendo de cerca de $38 \%$ com a compactação no sulco de plantio. Os aumentos observados com a compactação sobre o sulco de plantio foram bem mais elevados do que os obtidos por Soares \& Carrão (1993), de $15 \%$ na produtividade do arroz cultivado em várzea, e por Portugal et al. (2013), de 17\% na produtividade do arroz de terras altas conduzido em plantio direto. Possivelmente isto foi devido às menores pressões de compactação utilizada por esses autores e/ou menor ocorrência de pragas no solo.

$O$ efeito da pressão de compactação sobre o sulco de plantio no controle de insetos-praga pode ser uma das causas da maior produtividade do arroz com o incremento dessa pressão. A compactação sobre o sulco de plantio, além de melhorar o contato do solo com as sementes de arroz, permitindo que elas absorvam água mais cedo e germinem mais rapidamente (Silva, 2006; Pinheiro et al., 2016b,c), também reduz o ataque de cupins no arroz de terras altas cultivado em plantio direto (Pinheiro et al., 2016a), sendo o benefício dessa prática reforçado quando associado ao tratamento de sementes com inseticidas (Barrigossi et al., 2011; Pinheiro et al., 2016a).

De acordo com Radford \& Allsopp (1987), a compactação do solo com a roda compactadora consistentemente e marcadamente aumentou o estabelecimento do sorgo e do girassol em solos 


\section{웅 \\ Revista Agrarian \\ ISSN: 1984-2538}

infestados por insetos na Austrália. Esses autores atribuíram essas respostas ao aumento no suprimento de água do solo e a redução do dano letal às sementes e plântulas causado por uma ampla faixa de espécies de insetos. A compactação sobre o sulco de plantio pode esmagar insetos grandes próximos das sementes, matando-os ou ferindo-os; pode restringir o movimento dos insetos através do solo e pode aumentar o suprimento de água do solo, permitindo que as plântulas escapem do dano por insetos pela mais rápida germinação e crescimento. Eles também relataram que o uso de inseticidas em adição às rodas compactadoras aumentou o estabelecimento das culturas em algumas situações.

Com base nos resultados do presente experimento constatou-se que as práticas de compactação sobre o sulco de plantio até $340 \mathrm{kPa}$ juntamente com o tratamento de sementes proporcionam incrementos significativos na produtividade de grãos do arroz de terras altas cultivado no SPD, provavelmente porque nesse sistema devido ao não revolvimento do solo e a presença de palha na superfície do solo, dificultam a maior aderência da semente ao solo, além disso, essas práticas, também auxiliam no controle dos insetos-pragas iniciais da cultura.

\section{Conclusões}

Em área sob plantio direto, a compactação sobre o sulco de plantio até $340 \mathrm{kPa}$ acarreta maior produtividade de grãos do arroz de terras altas cultivado no sistema plantio direto;

O tratamento de sementes proporciona incrementos significativos na produtividade de grãos do arroz de terras altas cultivado no sistema plantio direto sobre palhada de braquiária.

\section{Referências Bibliográficas}

BARBOSA, L.H.A.; MATA, W.M.; FERREIRA, E.P.B.; DIDONET, A.D. Produtividade do arroz de terras altas após cultivo de plantas de cobertura no Cerrado goiano. Revista Brasileira de Agroecologia, v.4, n.2, p.200-203, 2009.

BARRIGOSSI, J.A.; PINHEIRO, V.; SILVA, J.G.; COBUCCI, T.; EIFERT, E.C.; SILVA, J.F.A.; ALVES, T.M. Efeito da compactação de sulco de plantio e de tratamentos de sementes na infestação de cupins em arroz de terras altas, em plantio direto.
In: $1^{\mathrm{o}}$ Simpósio Brasileiro de Termitologia, Anápolis. Anais, UEG, 2011. CD-ROM.

BARRIGOSSI, J.A.F.; FERREIRA, E. Tratamento de sementes de arroz com inseticidas: efeito sobre os insetos e rendimento de grãos. Santo Antônio de Goiás, Embrapa Arroz e Feijão. 2p. 2001.

COLLARES, G.L.; REINERT, D.J.; REICHERT, J.M.; KAISER, D.R. Qualidade física do solo na produtividade da cultura do feijoeiro num Argissolo. Pesquisa Agropecuária Brasileira, v.41, n. 11, p.1663-1674, 2006.

CRUSCIOL, C.A.C.; COSTA, A.M.; BORGHI, E.; CASTRO, G.S.A.; FERNANDES, D.A. Fertilizer distribution mechanisms and side dress nitrogen fertilization in upland rice under no-tillage system. Scientia Agricola, v.67, n.5, v.562-569, 2010.

FAO. Aquastat. Disponível

em http://www.fao.org/nr/water/aquastat/data.

Acessado em: 10 de novembro de 2015.

FAROOQ, M.; KOBAYASHI, N.; WAHID, A.; ITO, O.; BASRA, S.M.A. Strategies for producing more rice with less water. Advances in Agronomy, v.101, p.351-388, 2009.

FERREIRA, E.; BARRIGOSSI, J.A.F.; SILVA, J.G.; STONE, L.F.; MOREIRA, J.A.A. Fatores influenciando o ataque de cupim rizófago em plantio direto de arroz de terras altas. Pesquisa Agropecuária Tropical, v.37, n.3, p.176-181, 2007.

MODOLO, A.J.; FERNANDES, H.C.; SCHAEFER, C.E.G.; SANTOS, N.T.; SILVEIRA, J.C.M. Efeito do teor de água do solo e da carga aplicada pela roda compactadora na velocidade de emergência da soja. Acta Scientiarum Agronomy, v.29, n.5, p.587-592, 2007.

NASCENTE, A.S.; CRUSCIOL, C.A.C. 2012. Cover crops and herbicide timing management on soybean yield under no-tillage system. Pesquisa Agropecuária Brasileira, v.47, n.2, p.187-192, 2012.

NASCENTE, A.S.; KLUTHCOUSKI, J.; RABELO, R.R.; OLIVEIRA, P.; COBUCCI, T.; CRUSCIOL, C.A.C. Desenvolvimento e produtividade de cultivares de arroz de terras altas em função do manejo do solo. Pesquisa Agropecuária Tropical, Goiânia, v.41, n.2, p.186192, 2011. 


\section{;.) \\ Revista Agrarian \\ ISSN: 1984-2538}

NASCENTE, A.S.; OLIVEIRA, P.; KLUTHCOUSKI, J.; FREITAS, R.J.; FAVARIN, J.L. Cultivares de arroz de terras altas afetadas pelo manejo do solo. Revista Brasileira de Ciências Agrárias, Recife, v.8, n.3, p.428-434, 2013.

PINHEIRO, V.; STONE, L.F.; BARRIGOSSI, J.A.F.; NASCENTE, A.S. Grain yield and termite damage in rice by compaction on the furrow and seed treatment. Pesquisa Agropecuária Brasileira, Brasília, v.51, n.11, p.1813-1820, 2016 .

PINHEIRO, V.; STONE, L.F.; NASCENTE, A.S. Soil management, seed treatment and soil compaction on the sowing furrows affect grain yields of upland rice genotypes. Australian Journal of Crop Science, Lismore, v.10, n.8, p.1112-1117, 2016b.

PINHEIRO, V.; NASCENTE, A.S.; STONE, L.F.; LACERDA, M.C. Seed treatment, soil compaction and nitrogen management affect upland rice. Pesquisa Agropecuária Tropical, Goiânia, v.46, n. 1, p.72-79, 2016 c.

PINHEIRO, V.; STONE, L.F.; BARRIGOSSI, J.A.F. Produtividade do arroz afetada pela subsolagem, compactação no sulco de semeadura e tratamento de semente. Revista Brasileira de Engenharia Agrícola e Ambiental, Campina Grande, v.20, n.5, p.395-400, 2016d.

PORTUGAL, J.R.; RODRIGUES, R.A.F.; ARF, G.H.S.; PERES, A.R.; SOUZA, E. Doses de nitrogênio associadas à inoculação com Azospirilllum brasilense e compactação do solo na linha de semeadura em arroz de terras altas. In: $8^{\circ}$ Congresso Brasileiro de Arroz Irrigado, Santa Maria. Anais, UFSM e Sosbai. v.2. p.794-797, 2013.

RADFORD, B.J.; ALLSOPP, P.G. Use of insecticides and a press wheel to control soil insects affecting sorghum and sunflower establishment in Southern Queensland. Journal of the Australian Entomological Society, v.26, n.2, p.161-167, 1987. REICHERT, J.M.; KAISER, D.R.; REINERT, D.J.; RIQUELME, U.F.B. Variação temporal de propriedades físicas do solo e crescimento radicular de feijoeiro em quatro sistemas de manejo. Pesquisa Agropecuária Brasileira, v.44, n.3, p.310-319, 2009.

SANTOS, H.G.; JACOMINE, P.K.T.; ANJOS, L.H.C.; OLIVEIRA, V.A.; LUMBRERAS, J.F.;
COELHO, M.R.; ALMEIDA, J.A.; CUNHA, T.J.F.; OLIVEIRA, J.B. Sistema brasileiro de classificação de solos. Brasília: Embrapa. $3^{\text {a }}$ ed. 353p. 2013.

SANTOS, A. B. DOS; STONE, L. F.; VIEIRA, N. R. DE A. A cultura do arroz no Brasil. Santo Antônio de Goiás: Embrapa Arroz e Feijão $2^{\mathrm{a}}$ ed. 1000p. 2006.

SAS Institute Inc. Statistical Analysis System user's guide. Version 9.0. Cary: Statistical Analysis System Institute. 513p. 2002.

SILVA, J.G. Desempenho de semeadora no plantio direto do arroz influenciado por tipos de sulcadores e de compactadores de sulcos. In: $2^{\circ}$ Congresso Brasileiro da Cadeia Produtiva de Arroz e $8^{\circ}$ Reunião Nacional de Pesquisa de Arroz, Brasília. Anais, Embrapa Arroz e Feijão. CD-ROM. 2006. SOARES, A.L.A.; CARRÃO, V.H. Plantio direto de arroz irrigado: uma ponte entre passado $e$ futuro. Porto Alegre: Monsanto. 32p. 1993. 